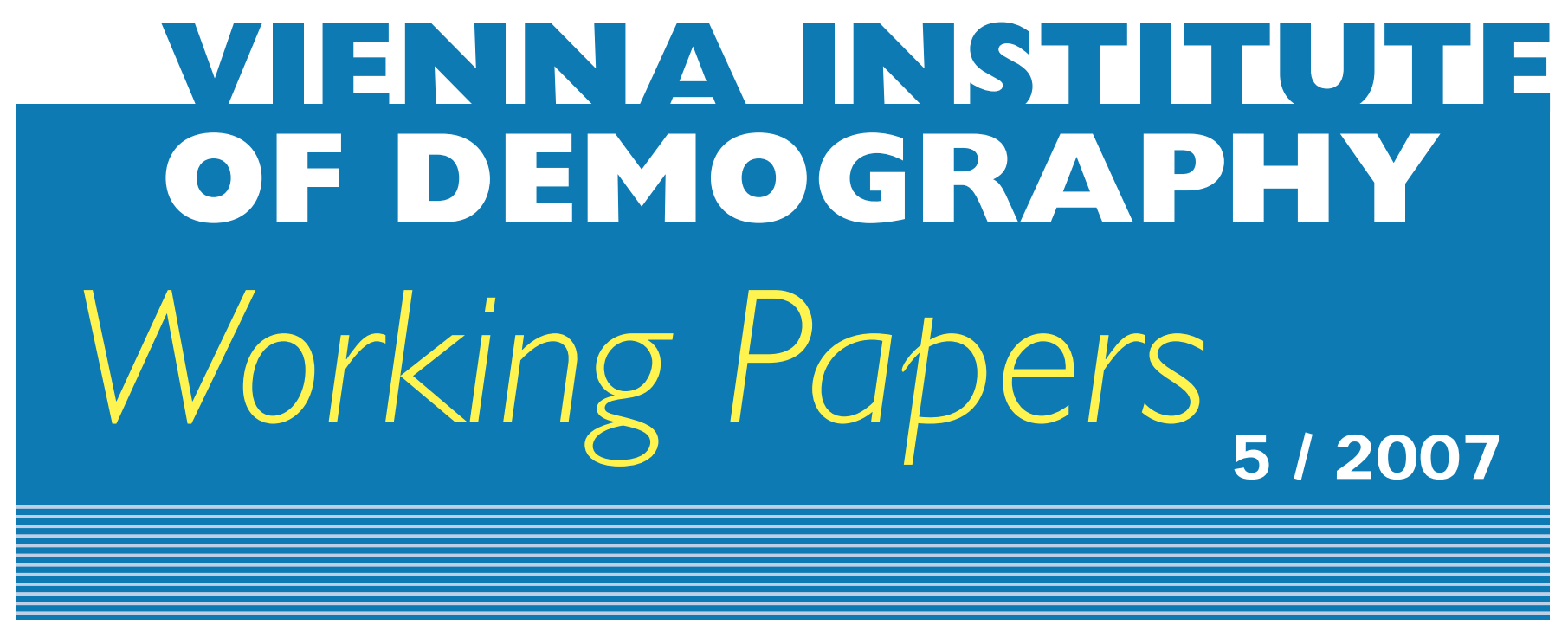

Belinda Aparicio Diaz, Thomas Fent, Alexia Prskawetz, and Laura Bernardi

\title{
Transition to parenthood: The role of social interaction and endogenous networks
}

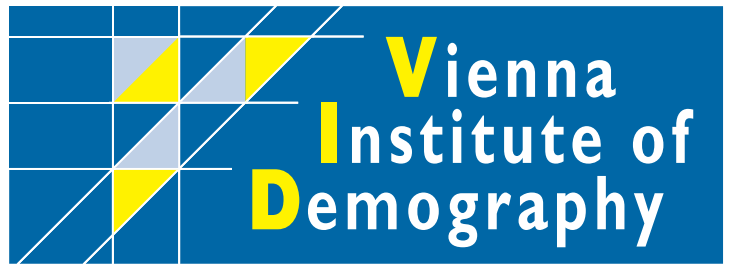

Vienna Institute of Demography Austrian Academy of Sciences

Wohllebengasse $12-14$

A-I040 Vienna $\cdot$ Austria

E-Mail:vid@oeaw.ac.at

Website: www.oeaw.ac.at/vid 


\begin{abstract}
Empirical studies indicate that the transition to parenthood is influenced by an individual's peer group. To study the mechanisms that create interdependencies across individuals' transition to parenthood and its timing we apply an agent-based simulation model. We build a one-sex model and provide agents with four different characteristics. Based on these characteristics, agents endogenously form their network. Network members then may influence the agents' transition to higher parity levels. Our numerical simulations indicate that accounting for social interactions can explain the shift of first-birth probabilities in Austria over the period 1984 to 2004 . Moreover, we apply our model to forecast agespecific fertility rates up to 2021 .
\end{abstract}

\title{
Keywords
}

Transition to parenthood, changes in age specific fertility rates, agent-based model, social interaction, endogenous network

\section{Authors}

Belinda Aparicio Diaz is a Research Scholar at the Vienna Institute of Demography of the Austrian Academy of Sciences, Vienna, Austria.

Alexia Prskawetz is a Senior Scholar at the Vienna Institute of Demography of the Austrian Academy of Sciences, Vienna, Austria, and a Research Associate at the Institute for Social and Economic Research at University Essex, Colchester, U.K.

Thomas Fent is a Research Scholar at the Vienna Institute of Demography of the Austrian Academy of Sciences.

Laura Bernardi is a Research Scientist at the Max Planck Institute for Demography in Rostock.

\section{Acknowledgements}

We are grateful to Robert D. Mare and participants of the session "Timing of Childbearing" at the Population Association of America 2007 Annual Meeting in New York for their helpful comments. 


\title{
Transition to parenthood: The role of social interaction and endogenous networks
}

\author{
Belinda Aparicio Diaz, Thomas Fent, Alexia Prskawetz, Laura Bernardi
}

\section{Introduction}

Human behavior, including childbearing behavior, is performed by socialized actors deeply rooted in a web of social relationships such as those created by kinship, love, power, friendship, competition or interest. Beliefs, norms, services, and goods are exchanged, traded, negotiated, and enforced within informal social networks of personal communities (Mitchell 1974). Within their social circle of relationships individuals may exchange information about possibilities and consequences of specific childbearing choices, learn about other persons' preferences, form expectations on their future choices, feel induced to conform to others norms about family-related behavior, and modify their interpretation of a specific behavior.

Interpersonal interactions among these relatively small groups of individuals produce social effects observable in macropatterns of behavior and demographic research on union and family formation has concentrated on the latter. Empirical evidence increasingly suggests social interaction as an important determinant of demographic behavior. Diffusion processes are currently an integral part of the literature on fertility decline (Knodel and van de Walle 1979, Watkins 1987, Cleland and Wilson 1987, Mason 1992, Pollak and Watkins 1993, Palloni 1998). While most research is carried out in developing countries some contagion models have been applied to union behavior in the European context (Nazio and Blossfeld 2003). Diffusion approaches build on the idea that social networks of kin, peers and institutions, in much the same way as markets and legal and the administrative system, are potential communication channels for ideas and behavior (Granovetter 1985, Rogers 1995).

In socio-demographic research, social determinants due to social interaction gained relevance when the empirical evidence provided by the European demographic history of the last century showed that regional patterns of fertility decline conformed very closely to linguistic, ethnic, and religious territorial boundaries. Some socio-demographers interpreted these patterns as the result of an undergoing ideational change diffusing ideals about smaller family size across political borders but following cultural lines (Watkins 1986; Bongaarts and Watkins 1996).

Consequently, the way in which attitudes, values, and norms spread within a population became central in research on family and fertility. The effects of social interaction mechanisms have been explored by using formal micro-analytical models, their effects have been studied through non-agent-based simulations, whose fit with observed fertility trends confirm the potential explanatory power of social interaction mechanisms (Rosero-Bixby and Casterline 1993, Montgomery and Casterline 1996, Kohler 2000, Kohler 2001). 
In all these applications, social interaction enters fertility explanations, both at the micro and macro level. Individual and population fertility are interdependent because the aggregation of individual fertility behavior produces externalities (like the erosion of norms, pressure to conform, and path dependency of the information exchange). Kohler (2001) efficiently summarizes the features of this micro-macro link: a) social interaction can alter the distribution of knowledge in the population and affect reproductive decisions under uncertainty by conveying information on the consequences of low fertility or on the dynamics of social change, b) it may establish a collective behavior among community members and initiate a fertility change when other factors would instead inhibit it, c) it may induce an endogenous transformation of social institutions and social norms.

The analysis of social mechanisms like social learning and social influence also plays an increasingly relevant role in demographic explanations of observed family formation patterns in contemporary Europe, such as the hypothesis formulated by Kohler et al. (2002) on the emergence of lowest-low fertility. However, the increasing inclusion of social interaction in the demographic theoretical framework matches with a relatively unrealistic model of social learning and social influence mechanisms (Chattoe 2003). As noted by Montgomery and Casterline, this refined modeling of the social processes reposes on a weak conceptualisation: "Little is known about learning mechanisms and the formation of perceptions in respect to demographic behavior. We are aware of no systematic investigation of what would seem to be a central issue" (Montgomery and Casterline 1996:159). Not only are the social mechanisms not specified in a satisfactory way; similar problems exist in defining the influential relationships on childbearing decision-making.

This lack of precision seems to constitute a general problem in the development of demographic behavior theory. Specifically, there is a certain agreement that demography suffers from a poor level of precision in theoretical construction, a statistical modeling that is either not, or not sufficiently, theory-driven, and the non-or hard-observability of important concepts and indicators involved in the theory (Burch 1996, de Brujin 1999). This weakness is partially due to the inadequateness of demographers' methodological toolbox in answering relevant demographic questions. The very recent inclusion of agentbased simulations and systematic and comparative in-depth investigations offer new possibilities to develop cognitive valid behavioral theories and to speculate on the consequences of alternative micro-macro feedbacks in order to explain demographic patterns (Billari and Prskawetz, 2003, Billari et al. 2003, Billari et al., 2006).

In this paper we introduce an agent-based model to study social interaction and, in particular, endogenous network formation and its implication for changes over time in the transition to parenthood. In the first place, such a model allows us to test whether changes in age-specific fertility experienced in the past can be explained by social interactions. Secondly, we can use this model to project age-specific fertility rates. Hence, our model we develop is not intended to explain the pattern of age-specific fertility but is designed to explain how this pattern changes over time.

In section 2 we introduce the theory and hypothesis of fertility transitions and social interaction and endogenous networks. Section 3 is devoted to the implementation of 
the model. The data we use to calibrate our model are discussed in section 4. Simulation results and fertility projections based on these simulation results are presented in section 5 . Finally, section 6 concludes our findings.

\section{Social interaction and fertility: theory and hypothesis}

Studies on fertility timing in developed countries have a strong explanatory role with respect to individual life course transitions. These contributions include educational, occupational, partnership, and geographical mobility histories. The postponement and increasing variability in these processes has often been associated with the observed delay in childbearing. To account for fertility preferences in general, family background variables or, more generally, early life experiences, constitute key indicators (Axinn et al. 1994).

Individuals' fertility behavior depends not only on family background variables, and life course paths, but also on the behavior and characteristics of other individuals as transmitted through social networks. Several authors have emphasized the importance of social interactions for fertility choices (Bongaarts and Watkins 1996; Montgomery and Casterline 1996; Bernardi 2003). As Bongaarts and Watkins (1996) argue, social interactions have at least three aspects: the exchange of information, the joint evaluation of its meaning, and social influence that constrains or encourages action. A comprehensive survey of fertility and social interactions is documented by Kohler (2001). To understand the divergence in the demographic behavior of different populations with relatively similar environmental conditions, Kohler argues for a combination of economic fertility theory (based on individual optimal and rational decision rules) and theories on social interaction (which incorporate the behavior of other members of the community/society). Another contribution that emphasizes the relevance of social interactions in the context of low fertility is by Kohler et al. (2002). They find that all lowest-low fertility countries, i.e. all countries with total fertility rate (TFR) less than 1.3 have experienced a sharp increase of the age of first birth and argue that this observation cannot be explained by changing socioeconomic incentives alone: Social interactions (either impersonal, for example, through the labor market or personal ones through peer groups for instance) must have induced multiplier effects or multiple equilibria. Lyngstad and Prskawetz (2006) on the basis of Norwegian register data investigate whether siblings' fertility decisions influence each other. Their results indicate that cross-siblings effects are relatively strong for the respondents' first birth, but weak for the second parity transition. A further interesting demonstration of how social interaction affect demographic behavior is given by Åberg (2003) who examined how the high-school peers of young Swedes influenced their propensity to marry. She found that the share of peers' married had positive effects on the marriage rate, indicating that social interaction is in part driving individuals' marital decisions.

So far, two avenues have been explored in the literature. On the empirical side, studies have aimed to identify or control for potential effects of social interaction on fertility (Bernardi 2003, 2007). On the more formal side, models have been developed that exogenously define the structure of the social network and investigate its implication on demographic behavior (Hernes 1972, Kohler 2001). In the present paper, we follow a 
recent development in the network literature that aims to endogenously build up the social network structure (Watts et al. 2002). For this purpose, we choose the framework of an agent-based model where the mechanisms underlying the behavior of each agent - in particular, the choice of social network, which in turn influences the fertility decision - is explicitly modeled.

For an individual, the social network (the set of "relevant others") consists of people who are close. Closeness is a general feature we shall exploit in what follows. In our context, the term "close" refers to a distance that may represent a spatial distance, but might as well represent a distance in terms of kinship, age, education, professional occupation, and so on. Closer individuals are more likely to be relevant others. The size and characteristics of an individuals' social network may themselves depend on the individuals' characteristics. For instance, the number of relevant others increases with age during youth and adulthood, at least up to ages that are important for processes such as getting married or having children (Micheli, 2000). The literature on social networks has further shown dependencies on additional individual characteristics and conditions under which the social network changes:

Age: The aging process produces a reduction in the size but an increase in the density of network partners since non-kins drop out (Wagner and Wolf 2001). But these changes seem to reflect life course transitions rather than aging itself.

Marital status and parental status: There is extensive and consistent evidence on the variation of network by marital and parental status, from cross-sectional comparative studies and longitudinal studies. Wellman et al. (1997) analyzed the changes in intimate ties of individual informal social networks in Toronto between 1968 and 1978. They find that the intimate relationships are relatively unstable over ten years. The median network has retained only about one quarter of its initial members and family situations rather than aging itself account for this turnover. Not surprisingly, marital change (getting married or divorced) seems to be the main triggering process for changes in the network: those who experienced it replaced almost all (94\%) of their network. Immediate and distant kin are the most persistent ties compared to friends and neighbors. The transition to parenthood seems to affect the circle of non-kin, whose members change even in the short one-year time frame after pregnancy (Ettrich and Ettrich 1995). The shift in the composition of social networks taking place after the transition to parenthood is consistent with the results from three similar studies in the United States and England, where parents' networks and non-parents networks are compared (Hammer et al. 1982). In addition to the positive association between rearing of children and increased emphasis on kin connections, the non-kin network composition shifts by including a higher number of friends as opposed to working relationships.

Employment status: Hammer et al. (1982) find that motherhood decreases the total network size essentially only for non-working mothers in the lowest social class. Moreover, they find that among mothers, the composition of the network between kin and non-kin members depends on the employment status. The number of kin within a network is higher for non-working mothers than for working mothers, whereas the number of non-kin network members is higher for employed mothers. 
Education and gender: Moore (1990) finds that most differences between gender in the social network composition of men and women in the US disappear when one controls for age, employment, and marital and parental status. Higher education or professional/managerial occupation entails a larger share of the network composed of nonkin (Moore, 1990, p.732, table 3). The only persistent difference is that women, compared to men, are more "kin-keepers" (the share of kin that characterizes women networks is larger when compared to men in similar structural positions).

We build up the social network of individuals based on a hierarchic structure of social groups, where each individual is part of one group for each relevant characteristic. We restrict the number of characteristics that determine the affiliation to a social group to three: age, education, and intended education. The choice of these three characteristics is based on the empirical findings summarized in the preceding paragraphs. Each individual is part of three social groups. Individuals within one group are close, and therefore more likely to belong to the same social network. Members of the social network influence the behavior of each other through interaction. In our model, we assume that as the share of mothers within the social network increases, the desire to give birth is intensified. In the next section we introduce the agent-based model, focusing on the implementation of the endogenous social network.

\section{Model implementation}

We set up a one-sex model that allows us to simulate the different life cycle stages of females. Although partnership plays a major role in the transition to parenthood, we refrain from including mate-search into our model since it would increase the complexity of the model and complicate the interpretation of the results.

Each individual agent has an identity number $i d$, four characteristics, and a social network that includes friends, siblings, and the agent's mother. ${ }^{1}$ The agent's characteristics are age $x$, education $e$, intended education $i e$, and parity $p$. We set the lower and upper age limit of reproduction to be equal at 15 and 49 years respectively and the maximum age of our agents as 95 years. Though agents older than 49 cannot give birth in our model, they still may influence other agents.

Education is an influential factor for social network formation and size (cf. Section 2) and thus becomes our second characteristic. We assume that all children, i.e., individuals younger than 15 , have no education at all beyond the compulsory years of education, hence their education is zero. For older individuals we distinguish three stages of education: primary and lower secondary, upper secondary, and tertiary.

Since education affects an agent's network not just on the day of graduation but has influenced it already during training, we further include intended education as an important characteristic of the agent. ${ }^{2}$ Based on these three characteristics - age, education and

\footnotetext{
${ }^{1}$ The agent's mother and siblings are not known for the initial population.

${ }^{2}$ The argument to include intended education in addition to attained education is based on the anticipatory
} 
intended education - an adult agent chooses on average $s$ members for her social network. These members influence the agent's decision on childbearing, i.e. her parity, which constitutes the fourth characteristic of the agent. We use six stages of parity, 0 to $5+$. An individual who gives birth to a child increases her parity by one. The agent's desire to give birth, that is to increase parity, is weakened or intensified by the influence of the social network snw. A summary of the agent's characteristics and parameters is shown in Table 1.

Table 1. Summary of the agent's characteristics and parameters.

\begin{tabular}{|c|c|c|}
\hline Agent variables & & values \\
\hline Identity number & $i d$ & $1-\mathrm{N}$ \\
\hline Education & $e$ & $0-3$ \\
\hline Intended education & $i e$ & $0-3$ \\
\hline Parity & $p$ & $0-5+$ \\
\hline Age at first birth & $a$ & $15-49$ \\
\hline Social network & snw & $0-\mathrm{N}-1$ \\
\hline
\end{tabular}

\section{Initial population}

We initialize the simulation with $N$ individuals and base our simulations on Austrian data, as defined in section 4. The Austrian age distribution for females constitutes the initial age distribution. The level of education of individuals aged 15 or older is assigned according to the Austrian age-specific educational distribution for females. On the basis of the assigned age and educational level, each agent is assigned her parity according to the Austrian age and education specific parity distribution of females.

Since most people finish their education before they turn 30 , we assume that the educational distribution at age 30 in the base year determines the intended education at earlier ages. ${ }^{3}$ Since empirical data show that transition to higher education is more common for non-mothers than mothers, we further consider the agent's parity when assigning the intended education. Hence, we need to take the agent's age $x$, parity $p$, and educational level $e$ into account when assigning intended education.

To assign intended education to a woman of age $x \in[y, y+5)$, parity $p$ and education level $e$ we start with the parity distribution by age and education from the census of the base year (see section 4). We denote $q_{y e}(p)$ the share of women at parity $p$ within the group of women at age $x \in[y, y+5)$ and at the level of education $e$. From the

analysis in life-course research discussed in Hoem and Kreyenfeld (2006).

${ }^{3}$ Of course, some individuals finish secondary or tertiary education later than age 30 . Therefore, it seems to be desirable to look at the educational distribution, for instance, at the age of 40 or 50 to be sure not to lose any individual obtaining a higher level of education during her life course. However, applying the educational distribution of older cohorts would result in a bias toward lower levels of education since higher education was not that common for older cohorts - this holds in particular for females. 
population census we obtain the shares of women aged 30 with level of education $e=1,2$, and 3: $q_{1}, q_{2}$, and $q_{3}$.

The shares of the parity-age-education-specific groups are then multiplied by the share of the corresponding educational level at age 30 to determine the probability for each level of intended education. Thus, for all agents aged 15 to 29 with the current level of education equal to 1 and parity $p$ the probability, $p r_{1}$, to be assigned an intended education $i e=1,2$, or 3 is given as

$$
p r_{1}(i e=i \mid e=1, p)=\frac{q_{i} q_{y i}(p)}{\sum_{j=1}^{3} q_{j} q_{y j}(p)}
$$

We do not allow an intended education ie lower than the already achieved education $e$. Therefore, agents with $e=2$ are assigned intended education $i e=2$ or 3 according to

$$
p r_{1}(i e=i \mid e=2, p)=\frac{q_{i} q_{y i}(p)}{\sum_{j=2}^{3} q_{j} q_{y j}(p)} .
$$

and agents with $e=3$ are assigned $i e=3$. Agents younger than 15 are not assigned an intended education, and for all individuals above the age of 28 the intended education ie is set equal to the actual education. ${ }^{4}$ Moreover, individuals at educational level 1 and older than 20 are also assigned actual education 1 as their intended education since transition between levels 1 and 2 practically happens only up to the age of 20 . Thus, the intended education is assigned randomly. It is based on the educational distribution of females at age 30 in the base year and subject to the following restrictions:

$$
\begin{aligned}
& i e \geq e \text { for all agents } \\
& i e=e \text { if }(x>28) \text { OR }(x>20 \text { AND } e=1)
\end{aligned}
$$

For agents with parity greater or equal to 1 an age at first birth $a$ is assigned according to the education-specific distribution of age at first births (cf. section 4). Since the behavior of women in training for education level $e$ is more comparable with the behavior of those who have already achieved the level $e$, we assign the age at first birth $a$ according to the agents' intended education ie. Once all initial agents have been assigned their individual characteristics, adult agents create their social network by choosing relevant others based on the three characteristics: age, education, and intended education.

\section{Simulation steps}

During each simulation step, each agent ages by one year and dies off at the age of 95 . Individuals younger than 15 are considered as children without education. At age 15 an

\footnotetext{
${ }^{4}$ Although some individuals advance to higher levels of education above that age limit, the period data on which we base the empirical estimations do not lead to strictly positive transition rates for that age group.
} 
individual becomes an adult with education level 1 and an intended education assigned on the basis of the education distribution of the population aged 30. Further she builds her own social network, which includes friends chosen according to the procedure described below. Agents born during the simulation already have a social network consisting of their mother and siblings. ${ }^{5}$ Though children do not exhibit their own social network of friends, they can nevertheless be part of one. When an agent turns 50, we assume that childbearing ceases. However agents older than 50 may still influence adults of childbearing age.

In the course of the simulation an adult agent may change her educational level. The age-specific educational transition rate is based on empirically observed transition rates for Austria (see section 4). From empirical data we know that non-mothers are more likely to increase their level of education, likewise are agents with a higher intended education. To achieve this, we scale the empirical education transmission rate by the following multiplier

$$
w(c)=\frac{\operatorname{ppae}(x, e+1, p) * h(e+1, i e)}{a(c) \sum_{x, p, i e} \operatorname{ppae}(x, e+1, p) * h(e+1, i e)},
$$

where $a(c)$ is the share of agents with the vector of characteristics $c=(x, e, i e, p)$. We assume that every agent may increase her educational level but postulate that those who have not yet attained their intended education are subject to a higher transition rate. The multiplier $h(e+1, i e)$ captures this assumption. It makes sure that within the set of agents who progress from the level of education $e$ to $e+1$ the share of those with intended education ie less than $e+1$ is smaller than the share of those with ie greater or equal $e+1$. For the transition from education level 1 to level 2 we apply the weights

$$
h(2, i e)=\left\{\begin{array}{lll}
\frac{1}{25} & \ldots & \text { if } i e=1 \\
\frac{12}{25} & \ldots & \text { if } i e=2 \\
\frac{12}{25} & \ldots & \text { if } i e=3
\end{array}\right.
$$

and for the transition from level 2 to level 3 we apply

$$
h(3, i e)=\left\{\begin{array}{lll}
\frac{1}{25} & \ldots & \text { if } i e=1 \\
\frac{1}{25} & \ldots & \text { if } i e=2 . \\
\frac{23}{25} & \ldots & \text { if } i e=3
\end{array}\right.
$$

\footnotetext{
${ }^{5}$ Through the inclusion of the mother as a peer, we attain the effect that the number of siblings influences the agent's fertility, in addition to the parity of the siblings themselves.
} 
In detail, in the group progressing from level 1 to level 2 the share of agents with $i e=1$ is 4 percent (i.e. 1/25) and the shares with $i e=2$ and $i e=3$ are 48 percent each $(12 / 25)$, while in the group progressing from level 2 to 3 the shares with $i e=1$ and $i e=2$ are 4 percent each (i.e. 1/25) and the share with $i e=3$ is 92 percent $(23 / 25)$, provided there are enough agents with each particular intended education.

As empirical data evidence that women with a higher parity have a lower transition rate to higher education - in particular there is a pronounced difference between mothers and non-mothers - we apply the multiplier ppae $(x, e+1, p)$, which represents the empirical share of women with parity $p$ at age $x$ and education $e+1$. Since these data are only available for five-year age groups we assume that half of the births happened after the transition to $e+1$ and the other half before the transition.

\section{Endogenous social network}

As mentioned in the introduction, our model should take into consideration that links in a social network may be based on any individual characteristic like age, kinship, love, power, friendship, professional occupation, geography, and so on. Thus, we have agents living in a multidimensional space, where each dimension represents one characteristic. Watts et al. (2002) introduced a searchable network taking into account that individuals partition the social world in more than one way. They applied this network to explain the process of delivering messages to a target person. In the sequel we will use a similar network structure for the diffusion of childbearing behavior.

The agents within such a searchable network exhibit network ties and individual characteristics. For our purpose we consider the characteristics age, education, and intended education to create a social network snw. Watts' approach envisions that individuals organize the society hierarchically into a series of layers, where the top layer represents the whole population, which is split according to the agent's characteristics into smaller subsets of individuals, which are likewise split into more specific subgroups. The social groups that are formed through this hierarchic division depend on the branching ratio $b$ and the group size $g$ of the lowest hierarchic level. Branching ratio and group-size are exogenous parameters, which, together with the number of individuals, determine the depth of the network hierarchy $l$. An agent is influenced by her social network snw concerning her childbearing behavior.

Since the number of agents is continuously changing in our simulations, the hierarchy depth $l$ needs to be recalculated in each simulation step. For this reason we suggest a slightly different variant as compared to the Watt's procedure. We fill the hierarchic groups sequentially with agents instead of literally splitting the population into groups. Through this approach we avoid missing groups and fluctuating group sizes which would occur due to the changing population size. The similarity among any two individuals, $d_{i j}$, is given by the height of their lowest common ancestor level in this hierarchy. If two individuals $i$ and $j$ belong to the same group, we define their similarity 
$d_{i j}$ equal to 1 , if they belong to different groups that are directly connected, their similarity becomes $d_{i j}=2$ and so on. For instance agents $i$ and $j$ in Figure 1 are in different groups which are not directly connected. To find the lowest common ancestor we need to trace back the branches two levels upwards. Therefore, the distance between $i$ and $j, d_{i j}$ is equal to three.

Figure 1 Partitioning of the population into groups of size $g=5$

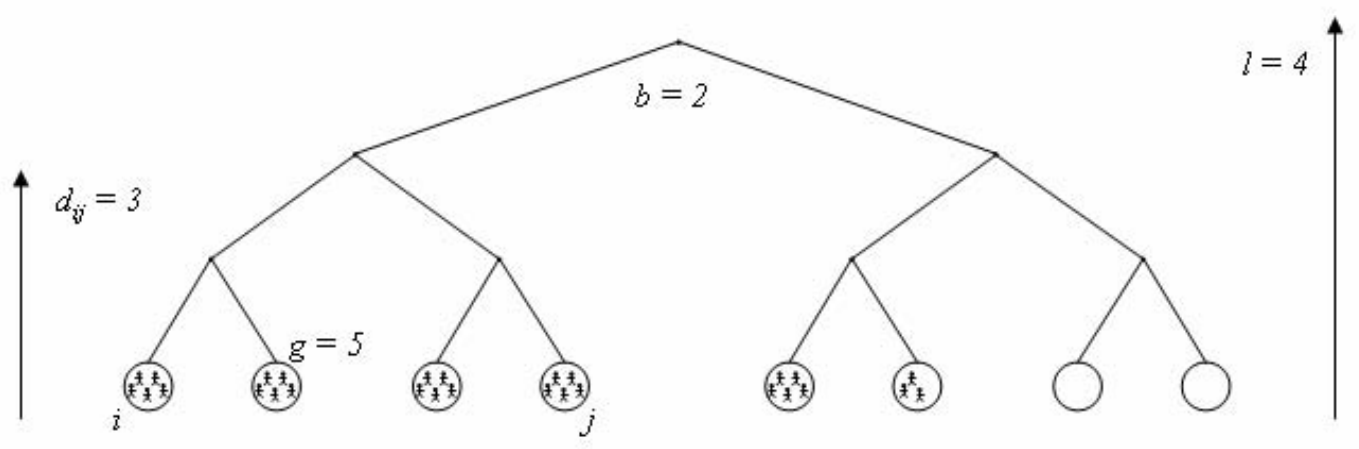

The probability of acquaintance (i.e. the probability of a link) between two individuals with a distance $d$ is given by

$$
p r_{2}(d)=c \exp (-\alpha d)
$$

with $\alpha$ being an adjustable parameter and $c$ being a constant required for normalization. Thus, even two individuals belonging to the same group are not necessarily connected. However, if the parameter $\alpha$, determining the agent's level of homophily, is assigned high values, the chance of a connection between individuals in the same group becomes high. To build up the social network an agent chooses a distance $d$ according to the above probability distribution (1) and then picks a friend uniformly among all individuals with distance $d{ }^{6}$ This procedure is repeated until an average number of peers, $s$, is found. The mean network size is an exogenous parameter. The actual number of friends for an agent is log-normally distributed.

Since individuals belong to three groups (by age, education, and intended education) the procedure described in the previous paragraph is repeated for each characteristic. Since we postulate that the characteristics are independent people belonging to the same group in one dimension may be far away from each other in another dimension. However, if there is a link established in one dimension due to the random process described above, the agent considers the chosen agent to be a part of her peer group. Whereas the social network snw of agents in the initial population consists only of

\footnotetext{
${ }^{6}$ Technically this procedure is implemented in the way that the agent draws a random number in the interval $(0,1)$ and the random number then determines the specific value of $d$ as determined by the probability distribution (1).
} 
members chosen by way of the above algorithm, the social network of agents created during the simulation also contains their mother and siblings.

Since networks are known to be unstable over time, we assume that each adult may exchange one or more members of her social network. Wellman (1997) found that after ten years the median network retains only $27 \%$ of its initial members. If an agent exchanges each member of her network with a probability $p r_{3}$, the probability for an initial member to still belong to the network after ten years is $\left(1-p r_{3}\right)^{10}$. Setting this expression equal to 0.27 implies a probability for each member of the particular agent's social network to be exchanged of $p r_{3}=0.129$. To implement these observed network changes we proceed as follows. Since there are $\left(\begin{array}{c}s_{i} \\ n\end{array}\right)$ possibilities to choose $n$ agents out of a network of size $s_{i}$, the probability to exchange exactly $n$ network members is given as

$$
p r_{4}(n)=\left(\begin{array}{c}
s_{i} \\
n
\end{array}\right) p r_{3}^{n}\left(1-p r_{3}\right)^{s_{i}-n} .
$$

After drawing a random number $n$ for each agent according to this probability distribution the agents removes $n$ randomly chosen members from their network and choose $n$ new members in the same way as during the initialization of the network.

\section{Social influence and parity transition}

An adult agent (aged between 15 and 49) may give birth to a child. The decision to change her parity status is influenced by her social network (Bernardi 2003, 2007). The propensity to have a first child increases with the share of parents within the agent's social network. Similarly the propensity to higher order births increases with the share of parents of higher order parity. To ensure that the social influence modeled at the individual level is "anchored" at the social influence we observe at the macro level, we postulate that the social influence vanishes if the parity distribution of an agent's network coincides with the parity distribution at the macro-level.

Formally, the social influence $s i$ for an agent of parity $p$ is modeled as a function of the difference between the share of mothers at parity $\tilde{p}>p$ within the social network, $r o p$, and in the whole population, $R O P$. The social influence positively (or negatively) affects the age- and parity-specific birth probabilities $b p r$ of Austria (see section 4).

To determine the social influence $s i$, we first define the relevant share of network members $\operatorname{rop}(p)$ whose parity exceeds the agent's parity $p$.

$$
r o p(p)=\frac{\#\left\{j: p_{j}>p \text { AND } j \in s n w\right\}}{\#\left\{j: p_{j} \geq p \text { AND } j \in s n w\right\}},
$$

where $p_{j}$ denotes the current parity of agent $j$ who is a member of agent $i$ 's social network snw, and $\#\left\{j: p_{j}>p\right.$ AND $\left.j \in s n w\right\}$ denotes the number of network members 
with parity greater $p$. Note, that for higher-order births we ignore (in the numerator of equation (3)) those agents within the peer network who are at parity $\tilde{p}<p .{ }^{7}$ Likewise, we compute the share of adult agents with parity greater $p, R O P(p)$, on the aggregate level,

$$
R O P(p)=\frac{\#\left\{j: p_{j}>p\right\}}{\#\left\{j: p_{j} \geq p\right\}}
$$

The difference between $R O P$ on the aggregate level and rop on the individual level determines the social influence on an agent's age- and parity-specific birth probability $\operatorname{bpr}(x, p)$. We model social influence as an s-shaped function with slope $\beta$,

$$
\operatorname{si}(p)=0.1 * \frac{\exp (\beta *(\operatorname{rop}(p)-R O P(p)))}{1+\exp (\beta *(\operatorname{rop}(p)-R O P(p)))}+0.95
$$

The parameter $\beta$ gives the intensity of the social influence when the share of network members of a specific parity diverges from the one on the aggregate level. Choosing $\beta=0$ results in a social influence of 1 in any case, which means that the influence of the social network is completely ignored. Lyngstad and Prskawetz (2006) point to a weaker influence for second births, thus we reduce the social influence for higher order births $s i(p>0)$ by decreasing $\beta$ to a fifth of its original value.

The value $s i$ is multiplied with the empirical age- and parity-specific birth probability at time $t, \overline{b p r}_{t}(x, p)$, to take the social influence into account. Thus, an agent $i$ at age $x$ gets assigned a probability of birth,

$$
\operatorname{bpr}_{i}(x, p)=\overline{b p r}{ }_{t}(x, p) \operatorname{si}(p)
$$

The multiplier given in (4) ensures that the birth probability $\operatorname{bpr}(x, p)$ of an agent $i$ facing a value of rop within her social network, which is equal to $R O P$ on the aggregate level is not being distorted. Put differently, when the social influence at the individual/ micro level is equal to the social influence at the macro level we assume that the social influence vanishes (i.e. it is equal to one). In case that the micro level share $\operatorname{rop}(p)$ differs from the macro level share $\operatorname{ROP}(p)$, the social influence is assigned a value in the range $(0.95,1.05)$ assuming that positive and negative deviations are symmetric. To also allow for an asymmetric social influence, but retaining the condition of $s i=1$ if $R O P(p)=\operatorname{rop}(p)$, we introduce the asymmetry through the slope $\beta$. We postulate an asymmetry that strengthens the positive and weakens the negative social influence. More precisely, a social influence function with slope $\beta=6$ and an asymmetry of $+30 \%$, as shown in Figure 2, actually leads to an influence function with slope $\beta=6-1.8=4.2$ for

\footnotetext{
${ }^{7}$ Bernardi et al. 2007 found that women who already have children do not refer to childless peers concerning former fertility decisions.
} 
negative influence, thus for agents with a lower $\operatorname{rop}(p)$ at the individual level than $R O P(p)$ at the macro level, and a slope $\beta=6+1.8=7.8$ for positive influence. In this way we achieve that the asymmetric social influence modeled at the individual level is again "anchored" at the social influence we observe at the macro level.

Figure 2 Symmetric and asymmetric social influence function

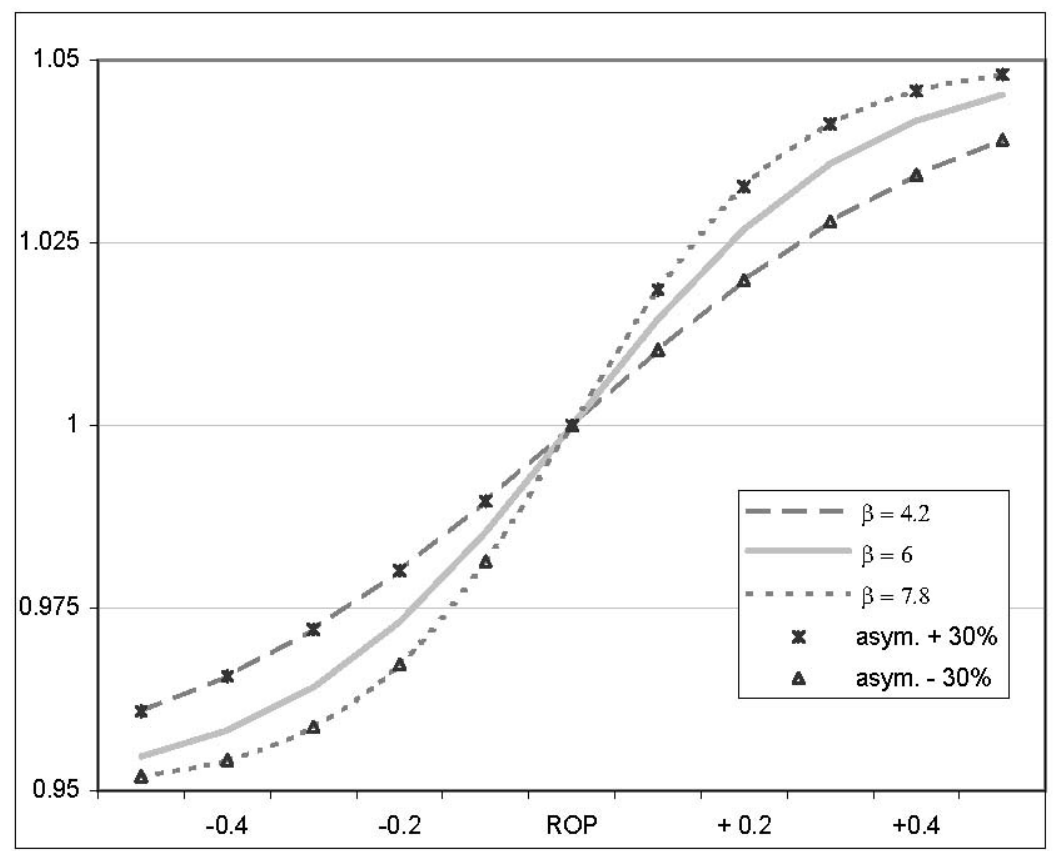

The individual changes on the micro level result in a modified probability to give birth at the macro level. Thus, the according probabilities at $t+1$ become

$$
\overline{b p r}_{t+1}(x, p)=\overline{b p r}_{t}(x, p) \overline{s i}_{t}(x, p)
$$

where $\overline{s i}(x, p)$ is the average of the social influence values si of all agents at age $x$ and parity $p$. These updated probabilities to give birth enter equation (5) for the next time step.

Transition to parenthood: After transition to parenthood an agent increases her parity by one. Since we work with a one-sex model we refer to the Austrian sex ratio at birth srb (see section 4) as a multiplier for the number of new agents. Hence only the female babies are created as new agents. Then they age each simulation step until arriving at adulthood (at age 15) when they choose their friends for the social network. During the childhood an agent's network only consists of the agent's mother and siblings, to whom the new agent is also added as a network member. 


\section{Data}

Age Distribution: For the initial population we alternatively use the age-distribution of Austrian females in 1981,1991 or $2001 .^{8}$

Figure 3 Age distribution for the Austrian female population in 1981 and for the initial population of one simulation starting from the same year.

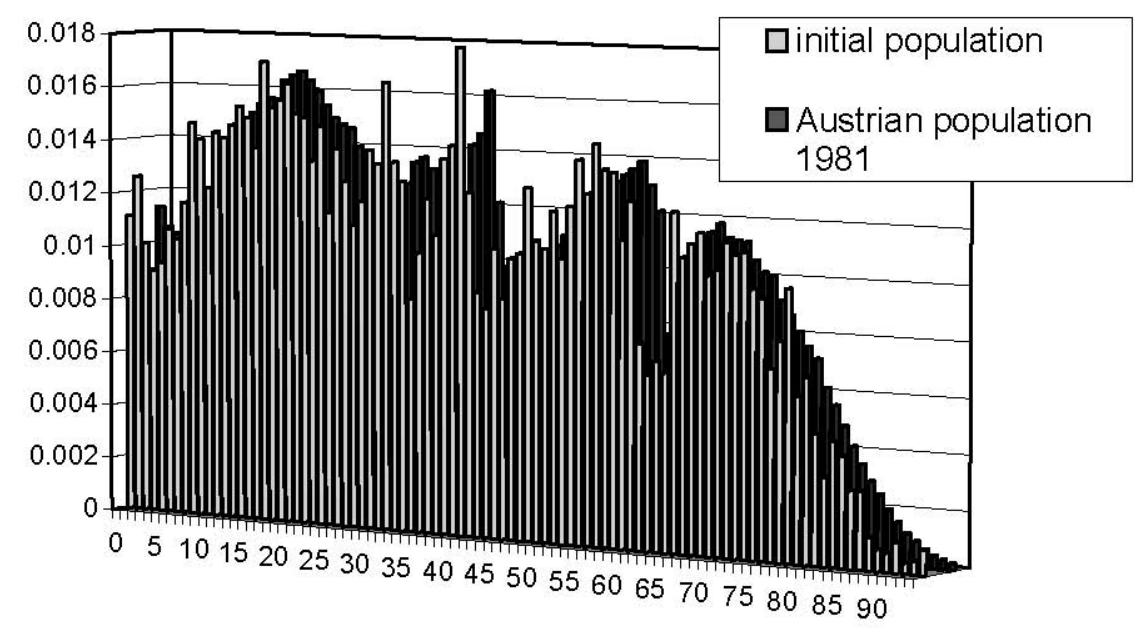

Distribution by Age and Education: We assign the level of education according to the agents' age. Agents younger than 15 receive education 0 , while all other agents are assigned as primary/lower secondary, upper secondary, or tertiary education according to the age-specific educational distribution of Austrian females in 1981, 1991 or $2001 .^{9}$

We distinguish (for adult agents) three stages of education, whereas the Austrian data we use as input distinguish 6 to 8 stages. We therefore merged these groups as follows: (i) primary/lower secondary education encompasses basic schooling (up to 9 years) and lower secondary education (including apprenticeships and normally between 10 and 12 years of schooling), (ii) upper secondary education encompasses the Austrian "Gymnasium" and its equivalents, such as corresponding nonacademic vocational training at a similar level, and (iii) tertiary education (including postgraduate studies, the training of primary school and gymnasium teachers, art academies, and so on).

Distribution by Age, Education, and Parity: Based on the Austrian distribution by age, education and parity of 1981,1991 or $2001^{10}$, we assign a corresponding parity

\footnotetext{
${ }^{8}$ Source: Statistik Austria (2005a), Table 8.7.

${ }^{9}$ Sources: Statistik Austria (1985), Table 13, Statistik Austria (1994), Table 14, Statistik Austria (2004), Table 15.

${ }^{10}$ Sources: Statistik Austria (1989), Table 50, Statistik Austria (1996), Table 48, Statistik Austria (2005c), Table 47. Analogous to the distribution by age and education, we merge the eight educational groups into three groups.
} 
for the initial agents.

Parity-specific Birth Probability by Age: The birth probabilities we apply in our simulations derive from computations by Tomas Sobotka on the basis of data provided by Statistik Austria. Unfortunately these data are only available from 1984 onwards. For simulations where we start with the 1981 initial population we need to apply the birth probabilities of 1984. For the other experiments we use the corresponding data from 1991 and 2001.

Educational Transition Rate by Age: The age-specific transition rates for educational groups are based on period measures. We alternatively start from the age and educational structure of the population in 1981, 1991, or 2001 and denote $F(x, e)$ the number of agents at age $x$ and with educational level $e$. For each age group we build the share of females having primary or lower secondary, upper secondary and tertiary education:

$$
f(x, e)=\frac{F(x, e)}{\sum_{e} F(x, e)} .
$$

By working with shares instead of absolute values we control for different cohort size. We then presume that the age and educational structure of the population stays constant over time and build the age-specific transition rates as follows:

$$
t(x, e)=\frac{f(x+1, e+1)-f(x, e+1)}{f(x, e)}
$$

where $t(x, e)$ indicates the transition rate at age $x$ from the educational level $e$ to level $e+1$ in the next time step.

Age at First Birth by Education: We use data on age at first birth, taking into account the mother's level of education from the census. Since these data are only provided for five-year age groups we interpolate the data with piecewise cubic hermite polynomials to obtain age at first birth by single years of age.

Sex Ratio at Birth: Since we do not include male agents in our model, we need the sex ratio at birth to calculate the number of new agents per simulation step. We again use Austrian data ${ }^{11}$ of the particular base year for this purpose.

\section{Simulation results}

In this section we discuss the results from simulations of the agent-based model introduced in the previous sections. We set the population size equal to $N=6000$ and present the

\footnotetext{
${ }^{11}$ Statistik Austria (2005b), Table 2.26.
} 
average over 200 simulation runs. Since our focus is on the transition to parenthood we primarily present developments of the mean age at first birth and the probability of a first birth. We also present the age-specific fertility rate for selected results.

As a benchmark, Figure 4 presents results of a simulation where we ignore social influence. We start with an initial population distributed according to the population in 1981 and exposed to the Austrian birth probabilities of 1984 and simulate it forward in time for 20 years. ${ }^{12}$ Obviously this benchmark model can neither replicate the increase in the mean age at birth (of two and a half years) nor the shift in age-specific first-birth probabilities during this time period. By neglecting the role of social influence we fail to replicate the fertility development that occurred between 1984 and 2004.

Figure 4 Simulation results for simulating 20 years starting from 1984 without social influence $(\beta=0)$.
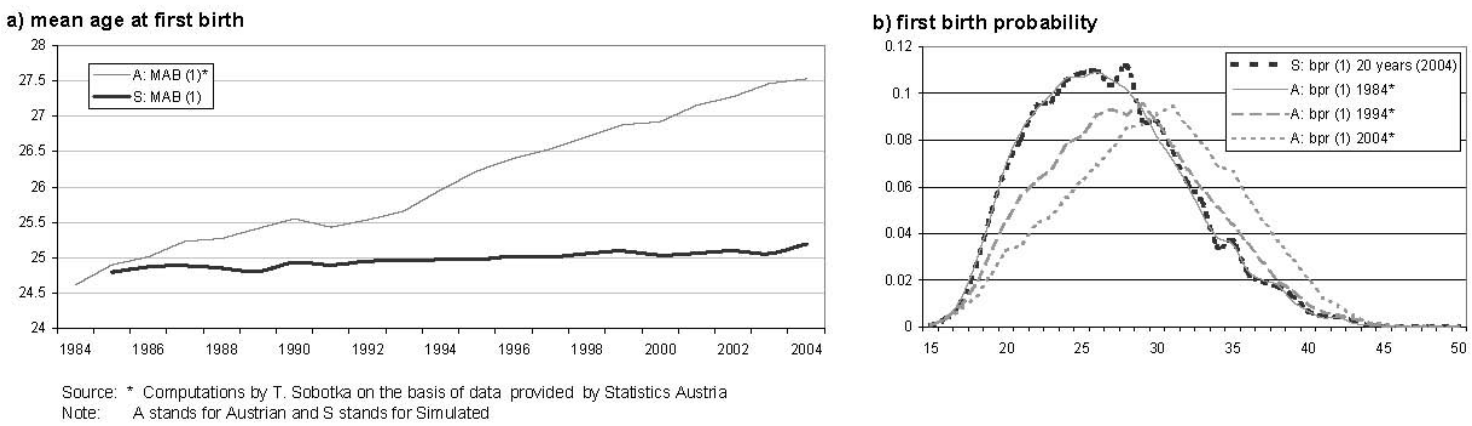

Source: * Computations by T Sobotka on the basis of data provided by Statistics Austria

Conds for Austrian and S stands for Simulated

Our experiments that take into account social influence indicated that most parameters have hardly any effect on the simulation results. The most influential parameters turned out to be the slope of the social influence function $\beta$ and the parameter $\alpha$, which gives the homogeneity within social networks. In Figure 5 we show the adjustment for these two parameters starting again from an initial population that is distributed according to the Austrian population of 1981 and is exposed to the birth probabilities of 1984. Starting from $\beta=6$ and $\alpha=0.75$ Figure 5a and Figure 5b, respectively, present the development of first-birth probabilities between 1984 and 1994 for alternative settings of $\beta$ and $\alpha$. All other parameters get assigned the following values: We set the group size of the hierarchy equal to 5 individuals $(g=5)$, the branching ratio $b$ equal to 2 (see Figure 1) and postulate an average size of the network of 10 peers ( $s=10$, Fliegenschnee, personal communication, 2006).

\footnotetext{
${ }^{12}$ Note that we have data on birth probabilities only from 1984 onwards. Hence, we need to combine the 1981 census data with 1984 birth probabilities.
} 
Figure 5 Simulation results for simulating 10 years starting from 1984 with different parameters $\alpha$ and $\beta$.
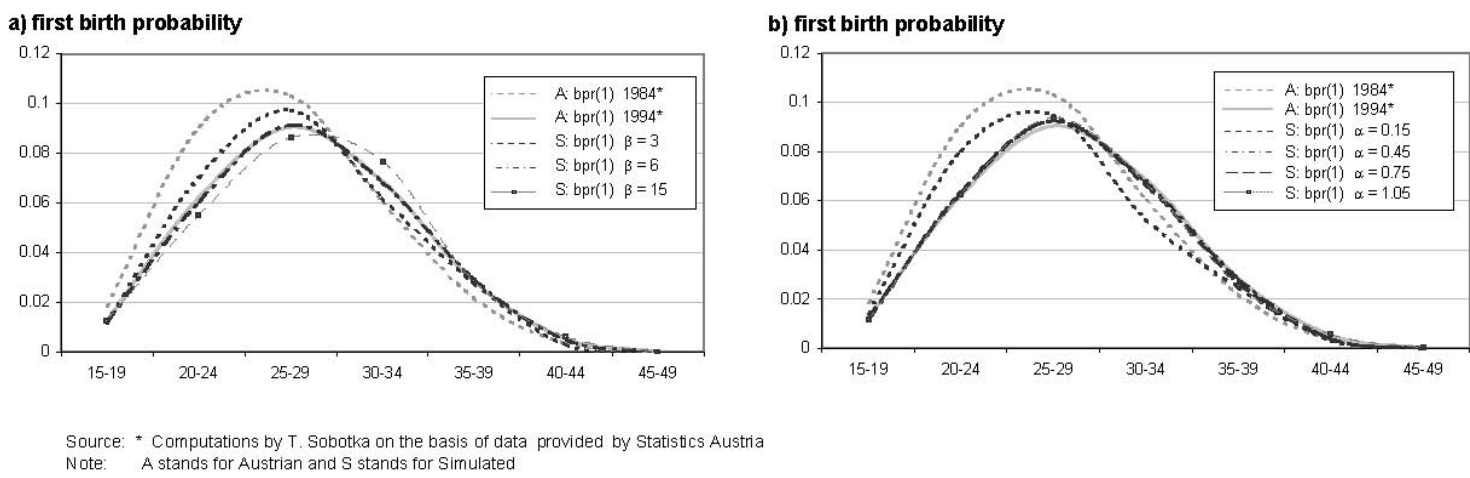

Compared to the results in Figure 4, where we ignore social influence, Figure 5 demonstrates the potential role of social influence to replicate the change in first-birth probabilities over time. A comparison of the simulation results with the actual first-birth probabilities in 1994 reveals that the choice of $\beta=6$ and $\alpha=0.75$ is appropriate.

Table 2. Default values for model parameters

\begin{tabular}{|l|c|c|}
\hline Model Parameters & \multicolumn{2}{c|}{ default } \\
\hline Number of initial agents & $N$ & 6000 \\
Number of simulation years & $y$ & 20 \\
Branching ratio & $b$ & 2 \\
Group size & $g$ & 5 \\
Homogeneity within social & $\alpha$ & 0.75 \\
networks & $\beta$ & 6 \\
$\begin{array}{l}\text { Slope of social influence } \\
\text { function }\end{array}$ & & \\
\hline
\end{tabular}

For extreme values of $\beta$, the postponement of first births would be overestimated ( $\beta=15$ ) or underestimated ( $\beta=3$ ). The parameter $\alpha$ also has an interesting effect on the results (Figure 5b). A rather small value of $\alpha$ (agents are relatively indifferent about the similarity of network members, thus they interact with any other agent regardless of their characteristics) leads to hardly any change of fertility behavior. Due to the mixture of groups all agents have about the same social influence, and thus are not forced to change their fertility behavior. For values of $\alpha$ above one half, the particular value of $\alpha$ no longer has a strong influence.

Figure 6 depicts the results of a set of simulations that replicate the observed fertility developments during the last decades. Austrian data from 1981 provide the basis for the initial population distribution, and agents at reproductive ages are exposed to the 
parity-specific birth probability of 1984 . Model parameters are set according to the default values discussed above and summarized in Table 2 . We run our simulations for 20 years up to the year 2004 and compare the results with actually observed data in Austria as provided by Statistik Austria. A thorough sensitivity analysis indicates that we obtain the best fit to actual data by postulating an asymmetry in the functional form of the social influence for the $1990 \mathrm{~s}$. Thus we add an asymmetry of 30\% (see Figure 2) during this decade and an asymmetry of $60 \%$ from 2000 onwards. The social influence on fertility behavior is therefore amplified if $r o p>R O P$ and dampened for $r o p<R O P$.

Figure 6 Simulation results for simulating from 1984

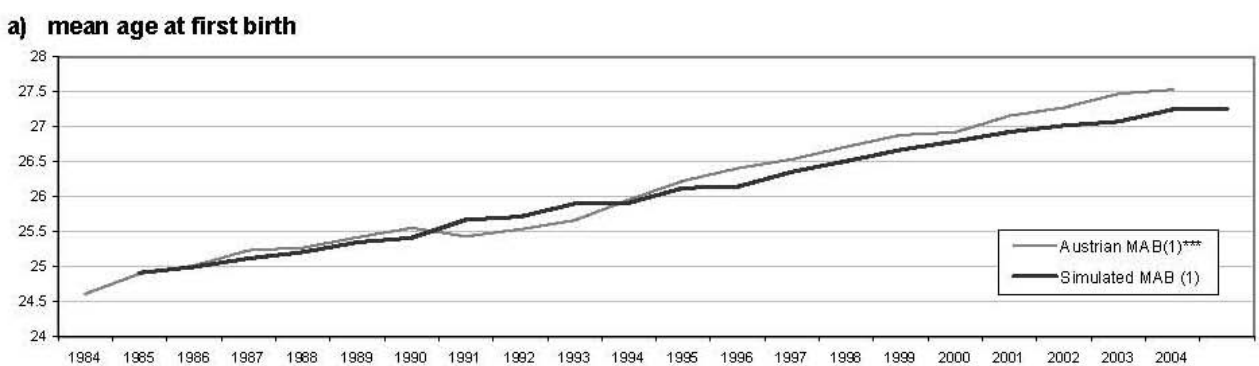

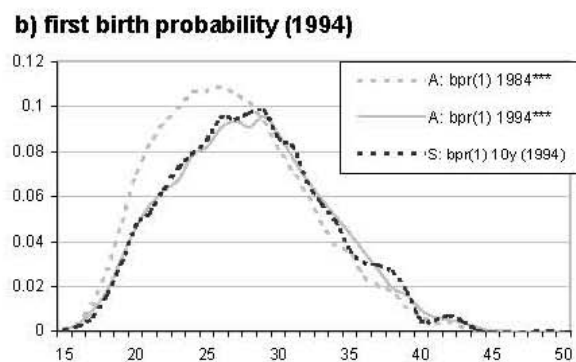

c) first birth probability (2004)
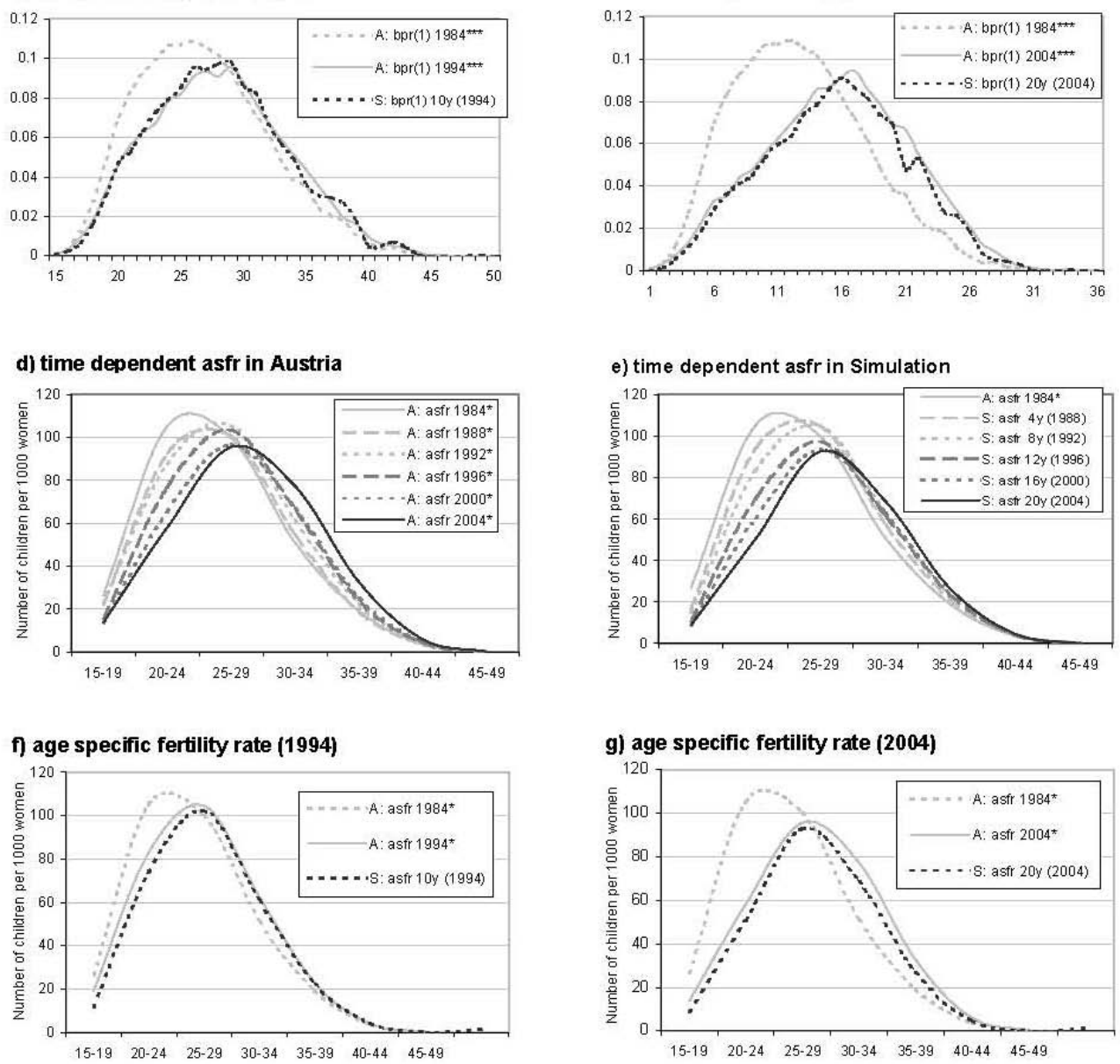

g) age specific fertility rate (2004)

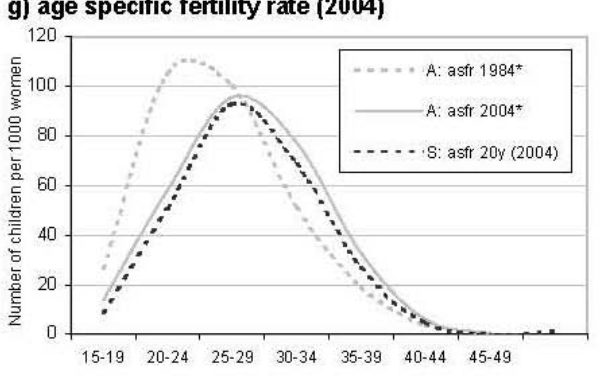

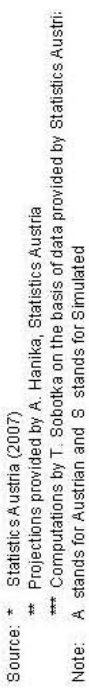


A comparison between the observed and simulated time series of the mean age at first birth validates the promising performance of our proposed model (Figure 6a). Agespecific probabilities of first birth in 10-year intervals are presented in Figures $6 \mathrm{~b}$ and $6 \mathrm{c}$. The three series depict respectively the empirical birth probability of the base year, 1984 and the year 1994 in Figure 6b and 2004 in Figure 6c together with the simulated birth probability of the latter years. In both cases the shape of the simulated curve is nearly identically to the empirical one. The remaining graphs, Figures $6 \mathrm{~d}$ to $6 \mathrm{~g}$ illustrate the evolution of the age-specific fertility rates over time. The first two charts verify the temporal progression of these rates in Austria (Figure 6d) and during the simulations (Figure 6e). The shift, presented in four-year steps, proceeds likewise in the simulation, as it did in reality. The similarity between simulations and empirically observed data becomes even more obvious when we consider the last two graphs (Figures $6 f$ and $6 \mathrm{~g}$ ) where we present a direct comparison between the Austrian age-specific fertility and the simulated ones after 10 years, hence in 1994 (Figure 6f) and for the year 2004 (Figure 6g). The results of our simulations slightly underestimate the rates for 1994. This difference is caused by a pronounced increase in probability for second births during this period. This rise is not replicated in a similar vein by our simulations.

In a further experiment we initialize the model with Austrian data from 1991 and run our simulation for 20 years up to 2011 . We apply the same set of parameters and the same asymmetry in the social influence function as in the previous simulations. Results for this experiment - both historical developments (from 1991 to 2001) and some first projections (to 2011) — are summarized in Figure 7. The mean age at first birth (Figure 7a) depicts the same increasing trend as in Figure 6a. The empirically observed line is slightly above the simulated one, as caused by a bend in the early nineties, which is not replicated by our model. After the first 10 years of the simulations, the probability of first birth comes close to the empirically observed curve in 2001 (Figure 7b). Further simulations for another 10 years yield the first-birth probabilities in 2011 (Figure 7c). Since similar data are not available from Statistik Austria, we compare the 2011 time series of first-birth probabilities with the corresponding (last obtainable) empirical data from 2005. The evolution of age specific fertility rates (empirically observed and projected ones by Statistik Austria for 2011 as well as simulated ones) from 1991 to 2011 is presented in Figures $7 \mathrm{~d}$ through $7 \mathrm{~g}$. Simulated fertility rates for 2001 (Figure 7f) overestimate the empirically observed rates (particularly for ages between 25 to 29). This difference can be explained by the extremely low fertility rate in Austria during 2001 as caused by a change in family policies (introduction of new child benefits in the following year). In 2001 the total fertility rate reached a low of 1.33 as compared to1.36 in 2000 and 1.39 in 2002 . The latter Figures are closer to the simulated fertility rate of 1.39 for the year 2001. 
Figure 7 Simulation results for simulating 20 years starting from 1991

\section{a) mean age at first birth}

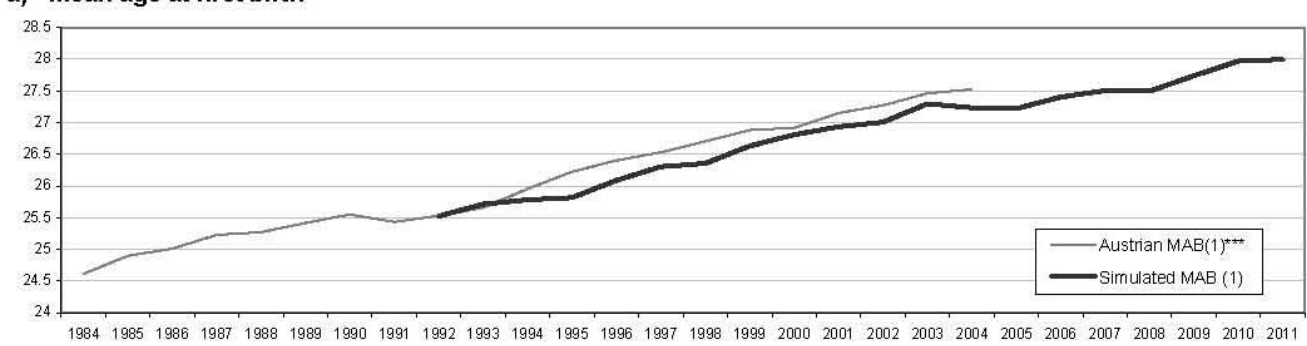

b) first birth probability (2001)

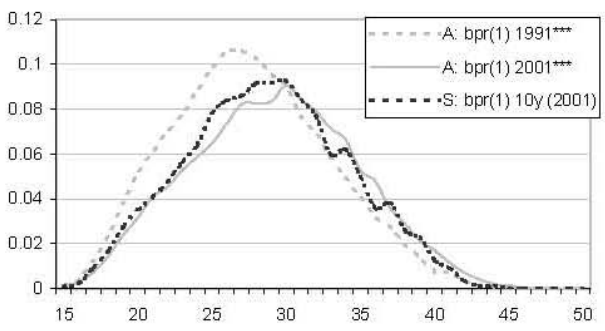

d) time dependent asfr in Austria

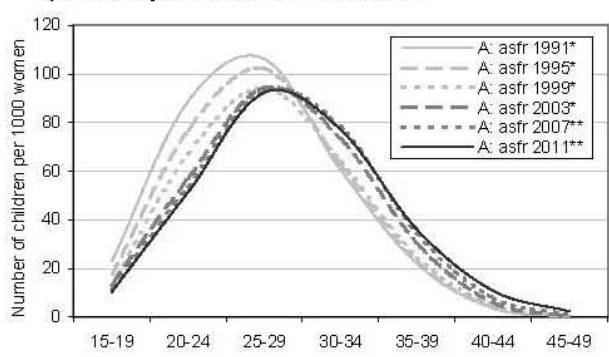

f) age specific fertility rate (2001)

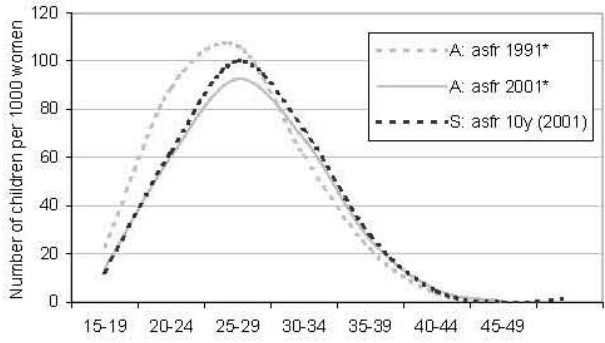

c) first birth probability (2011)

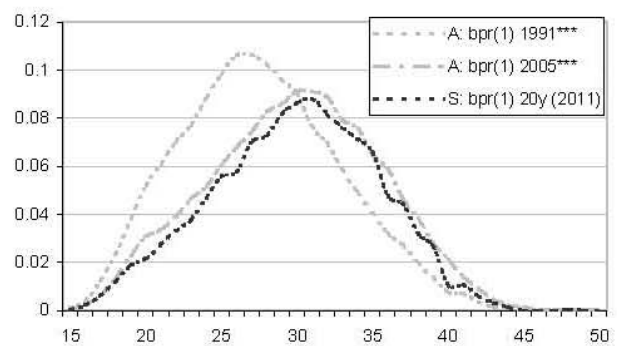

e) time dependent asfr in Simulation

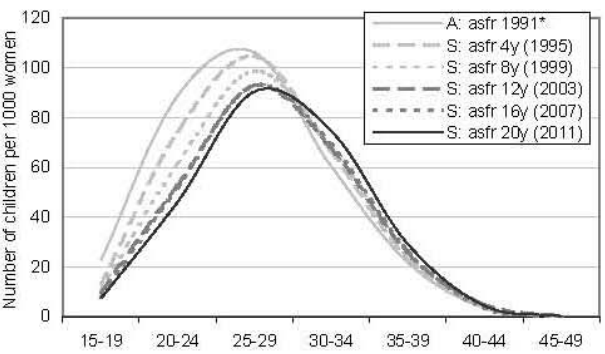

g) age specific fertility rate (2011)

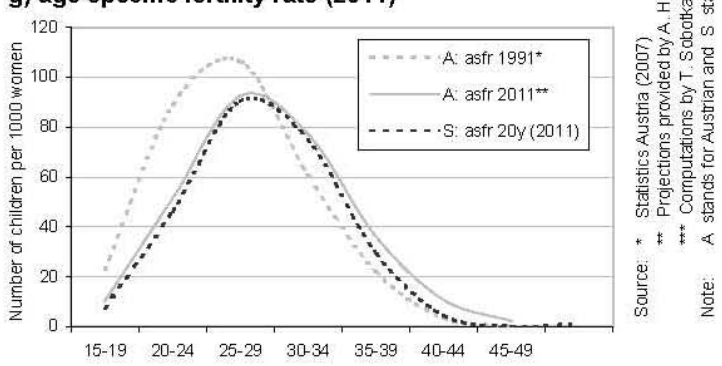

So far, we have demonstrated that our model is capable of reproducing shifts in the timing of fertility that occurred during the last decades. Note that our model is not intended to explain the general pattern of age-specific fertility — which is given as an explicit input - but is designed to explain how this pattern changes over time. Next we apply our model to project future trends of fertility and compare our projections to the age-specific fertility 
assumptions applied by Statistik Austria for their recent population projection (Hanika, 2006). While population forecasts are usually based on time series extrapolation of recent fertility trends combined with some expert knowledge, our approach has a theoretical foundation. We use a causal model to explain trends in timing of fertility rather than continuing existing trends. Sanderson (1998) argues that combining forecasts from causal models with standard forecasts results in more accurate predictions if the forecast errors of the two different approaches are not highly correlated.

Figure 8 Simulation results for simulating 20 years starting from 2001
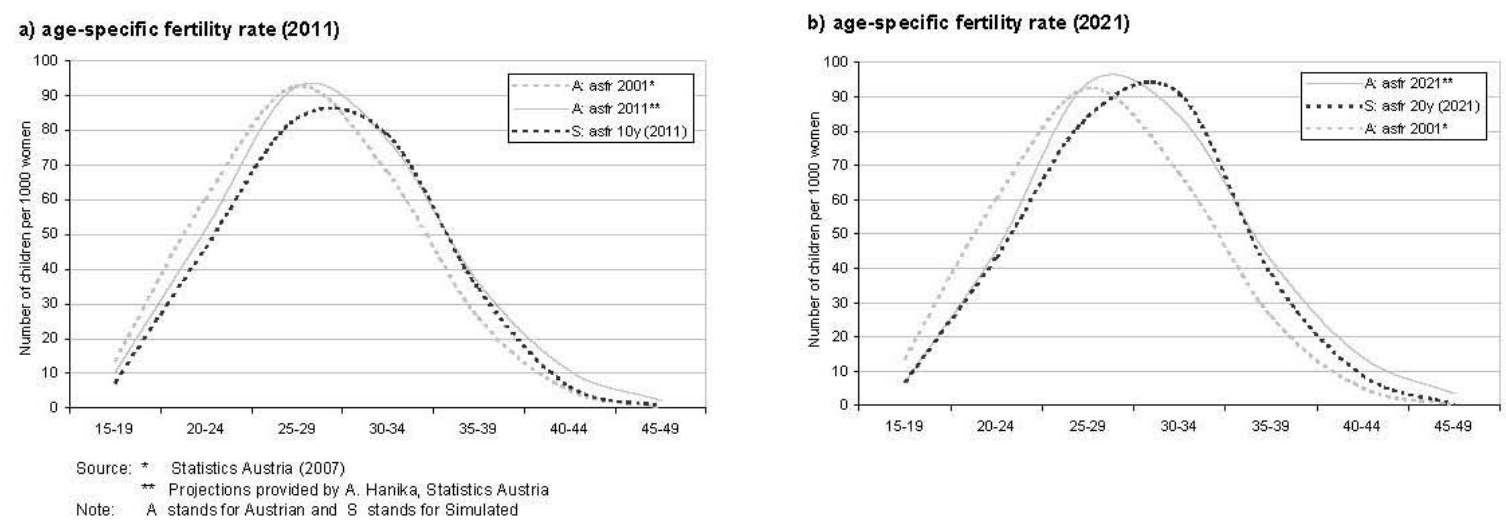

Starting from the year 2001, we forecast fertility rates to 2021. We retain the model parameters as in previous simulations and postulate an increase in the asymmetry of the social influence from $30 \%$ prior to 2010 to $90 \%$ from 2010 onwards. Figure 8 depicts simulated age-specific fertility rates and those assumed by Statistik Austria respectively for 2011 and 2021. The simulated rates for 2011 (Figure 8a) are considerably lower compared to the assumptions by Statistik Austria. This underestimation of fertility rates in our simulations is mainly caused by the exceptionally low fertility rates in Austria in 2001, which is the base year of the current simulation. The relatively low birth probabilities of 2001 , especially for the age group 25 to 29 , are passed on through the whole simulation, implying also the quite low fertility rate in 2021 (see Figure 8b).

Figure 9 Simulation results for simulating 30 years starting from 1991
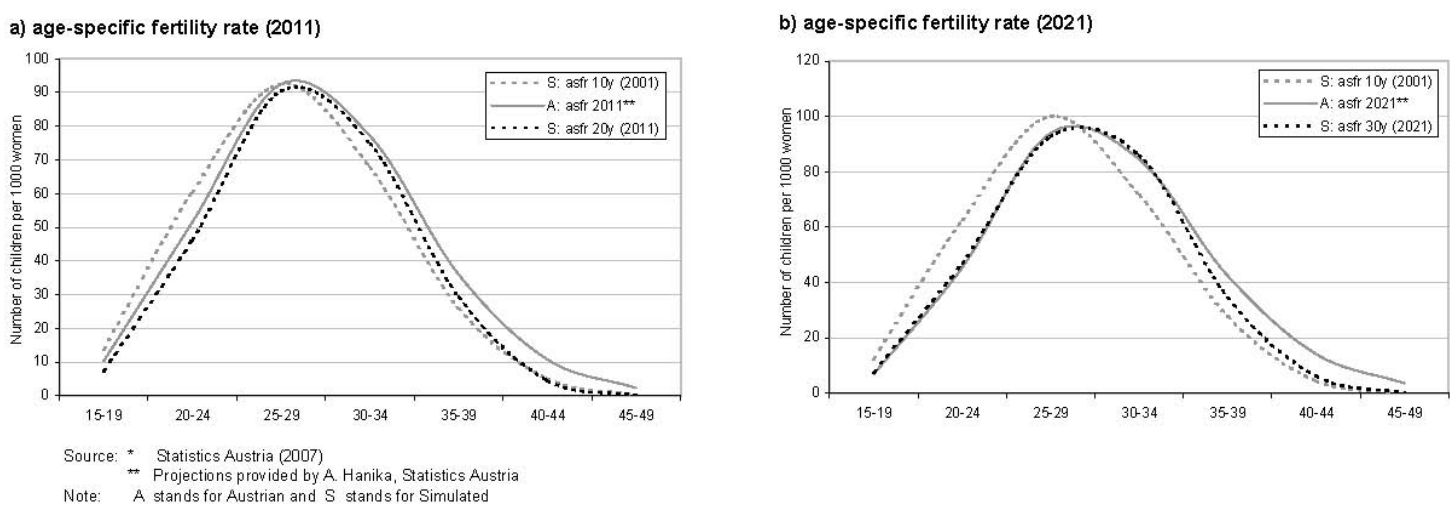

Note: A stands for Austrian and $S$ stands for Simulated 
As we consider the year 2001 not to be an appropriate base year, due to its exceptionally low fertility rates, we project fertility rates for the years 2011 and 2021 again using 1991 instead of 2001 as the base year. The results are depicted in Figure 9. The shape of the age-specific fertility rate as projected by our simulations for 2011 and 2021 is rather similar to the corresponding rates postulated by Statistik Austria with one exception. Fertility rates at higher ages (above age 40 ) are projected to be lower in our simulations as compared to the assumptions underlying the projections by Statistik Austria.

\section{Conclusions}

As recently shown by various authors (Kohler et al. 2002, Bernardi 2003), social learning and social influence play an increasing role in demographic explanations of observed family formation patterns in contemporary Europe. The increasing inclusion of social interaction in the demographic theoretical framework however matches with a relatively unrealistic model of the mechanisms that underlie those social interactions.

We propose to apply the methodology of agent-based models (ABMs) to study the role of social interaction for explaining observed demographic patterns. Such models allow "thought experiments that explore plausible mechanisms that may underlie observed patterns" (Macy and Miller 2002, p.147). Different from micro or macro simulations, ABMs provide a theoretical bridge between the micro and macro level. The dynamic bottom-up approach of ABMs - to explain global patterns by simple local interactions - is particularly useful when aiming to explain trends in fertility timing and quantum over the last decades.

In this paper we have presented an $\mathrm{ABM}$ on the transition to parenthood, focusing on the role of social interaction and providing an endogenous formation of the social network. Calibrating our model to Austrian data, we have shown that our model captures the observed changes in the timing and quantum of fertility over the last three decades to a high degree. One should keep in mind that the model is not intended to explain the pattern of age-specific fertility in general but to capture the cause and the extent to which this pattern changes over time. We then applied our model to forecast age-specific fertility rates for the next two decades. Our framework differs from common practice in population forecasts that either rely on extrapolations of past trends or expert opinions. Instead, we propose a causal model that allows us to project demographic behavior.

The next step is to apply our model to different European countries and test its validity. Within the framework of our ABM we can experiment with alternative mechanisms that may underlie the timing and quantum of fertility in different social environments. The exploration of plausible mechanisms that underlie observed patterns is the main challenge confronting demographers as they propose efficient explanations of past trends and provide reliable projections of future demographic developments. To demonstrate the feasibility of such an approach by applying it to the topic of the transition to parenthood has been the main aim of the current paper. 


\section{References}

[1] Aberg Y. (2003). Social Interactions: Studies of Contextual Effects and Endogenous Processes, Doctoral Dissertation, Department of Sociology, Stockholm University.

[2] Aparicio Diaz, B., Fent, T. (2006), An Agent-Based Simulation Model of Age-atMarriage Norms. In: Billari, F. C., Fent, T., Prskawetz, A., Scheffran, J. (eds.), AgentBased Computational Modelling. Heidelberg: Physica Verlag, pp. 85-116.

[3] Axinn, W.G., Clarkberg, M.E., Thornton, A. (1994) Family Influences on Family Size Preferences. Demography, 31(1), 65-79.

[4] Bernardi, L. (2003). Channels of social influence on reproduction. Population Research and Policy Review 22, pp. 527-555.

[5] Bernardi, L., Keim, S., von der Lippe, H. (2007). Social Influence on Fertility: A Comparative Mixed Methods Study in Eastern and Western Germany, Journal of Mixed Methods Research 1(1), 23-47.

[6] Billari, F., Fent, T., Prskawetz, A., Scheffran, J. (2006). Agent-Based Computational Modelling: Applications in Demography, Social, Economic and Environmental Sciences. Physica Verlag.

[7] Billari, F. C., Prskawetz, A. (2003) Agent-Based Computational Demography: Using Simulation to Improve Our Understanding of Demographic Behaviour. Physica Verlag.

[8] Billari, F., Prskawetz, A., Fürnkranz, J. (2003) On the Cultural Evolution of Age-atMarriage Norms. In: Billari, F. C.; Prskawetz (eds.) Agent-Based Computational Demography. Physica Verlag, pp. 139-158.

[9] Bongaarts, J. Watkins, S. C. (1996) Social interactions and contemporary fertility transitions. Population and Development Review 22(4), pp. 639-682.

[10] Burch (1996) Icons, strawmen and precision: Reflections on demographic theories of fertility decline. The Sociological Quarterly 37 [1996] 59-81.

[11] Chattoe, E. (2003) The Role of Agent-Based Modelling in Demographic Explanation. In: Billari, F. C.; Prskawetz (eds.) Agent-Based Computational Demography. Physica Verlag, pp. 41-54.

[12] Cleland, J. and Wilson, C. (1987) Demand theories of the fertility transition: An iconoclastic view, Population Studies 41(1): 5-30.

[13] de Bruijn, B.J. (1999) Foundations of Demographic Theory. Choice, Process, Context. Amsterdam: Thela Thesis.

[14] Ettrich, C. and K. U. Ettrich, (1995) Die Bedeutung sozialer Netzwerke und erlebter sozialer Unterstützung beim Übergang zur Elternschaft - Ergebnisse einer Längsschnittstudie; Psychologie in Erziehung und Unterricht, 42(1), 29-39. 
[15] Granovetter, M. (1985) Economic action and social structure: The problem of embeddedness, The American Journal of Sociology 91(3): 481-510.

[16] Hammer, Gutwirth, Phillips (1982) Parenthood and Social Networks; Soc Sci Med. 1982;16(24):2091-100.

[17] Hanika, A. (2006) Zukünftige Bevölkerungsentwicklung Österreichs 2006 bis 2050 (2075): Neudurchrechnung der Bevölkerungsprognose, Statistische Nachrichten 10/2006: $868-885$.

[18] Hoem, J. and M. Kreyenfeld (2006) Anticipatory analysis and its alternatives in lifecourse research. Part I: The role of education in the study of first childbearing. Demographic Research 15: 461-484.

[19] Knodel, J. and van de Walle, E. (1979) Lessons from the past: policy implications of historical fertility studies, Population and Development Review 5(2): 217--245.

[20] Kohler, H.-P. (2000) Social interaction and fluctuations in birth rates. Population Studies, 54, 223-237.

[21] Kohler, H.-P. (2001) Fertility and Social Interaction. An Economic Perspective. Oxford: Oxford University Press.

[22] Kohler, H.-P., Billari, F. C., Ortega, H.-A. (2002) The emergence of lowest-low fertility in Europe during the 1990s. Population and Development Review 28(4): 641-680.

[23] Lyngstad, T.H., Prskawetz, A. (2006) Do siblings' fertility histories influence each other? mimeo.

[24] Macy, M.W. and Willer, R. (2002) From factors to actors: computational sociology and agent-based modeling. Annual Review of Sociology 28: 143-1466.

[25] Mason, K. O. (1992) Culture and the fertility transition: Thoughts on theories of fertility decline, Genus 48(3-4): 1--14.

[26] Micheli, G. (2000) Kinship, family and social networks: The anthropological embedment of fertility change in Southern Europe. Demographic Research, 3(13).

[27] Mitchell, J.C. (1974) Social Networks. Annual Review of Anthropology 3: 279-299.

[28] Montgomery, M.R.and Casterline, J.B. (1996) Social learning, social influence and new models of fertility. In: J.B. Casterline, R.D. and K.A. Foote (eds.), Population and Development Review (Supplement 22: Fertility in the United States: new patterns, new theories), pp. 151-175.

[29] Moore, G. (1990) Structural Determinants of Men's and Women's Personal Networks'. American Sociological Review 55(5): 726-735.

[30] Nazio, T., Blossfeli, H.-P. (2003) The Diffusion of Cohabitation among Young 
Women in West Germany, East Germany and Italy. European Journal of Population, 19(1), 47-82.

[31] Palloni, A. (1998) Theories and models of diffusion in sociology. Working paper. University of Wisconsin. Centre for Demography and Ecology.

[32] Pollak, R. and Watkins, S. (1993) Cultural and economic approaches to fertility: proper marriage or misalliance? Population and Development Review, 19(3): 467-496.

[33] Rogers, E. (1995) The diffusion of innovations. New York: Free Press.

[34] Rosero-Bixby, L., Casterline, J. (1993) Modeling diffusion effects in fertility transition. Population Studies, 47(1), 147-167.

[35] Sanderson, W. C. (1998) Knowledge can improve forecasts: A review of selected socioeconomic population projection models. Population and Development Review, 24, Supplement: Frontiers of Population Forecasting, 88-117.

[36] Statistik Austria, (1985) Volkszählung 1981 Hauptergebnis II.

[37] Statistik Austria, (1989) Volkszählung 1981, Eheschliessungs- und Geburtenstatistik.

[38] Statistik Austria, (1994) Volkszählung 1991 Hauptergebnis II.

[39] Statistik Austria, (1996) Volkszählung 1991, Haushalte und Familien.

[40] Statistik Austria, (2004) Volkszählung 2001 Hauptergebnis II.

[41] Statistik Austria, (2005a) Demographisches Jahrbuch 2003.

[42] Statistik Austria, (2005b) Statistisches Jahrbuch Österreich 2004.

[43] Statistik Austria, (2005c) Volkszählung 1991, Haushalte und Familien.

[44] Wagner, M. and Wolf, C. (2001) Altern, Familie und soziales Netzwerk. Zeitschrift für Erziehungswissenschaft, 4, 529-554.

[45] Watkins S. (1987) The fertility transition: Europe and the third world compared, Sociological Forum 2(4): 645-673.

[46] Watkins, S. (1986) Conclusions. In: A Coale and S.Watkins (eds.), The Decline of Fertility in Europe. Princeton: Princeton University Press, pp. 420-449.

[47] Watts, D. J., Dodds, P. S., and Newman, M. E. J. (2002) Identity and search in social networks. Science, 296(5571): 1302-1305.

[48] Wellman, B., Wong, R.Y., Tindall, D., Nazer, N. (1997) A decade of network change: Turnover, persistence and stability in personal communities. Social Networks 19 (1997) 27-50. 


\section{VIENNA INSTITUTE OF DEMOGRAPHY}

\section{Working Papers}

Ediev, Dalkhat M, On Projecting the Distribution of Private Households by Size, VID Working Paper 04/2007.

Biehl, Kai und Thomas Fent, Vorausschätzungen für die Entwicklung der Gesamtbevölkerung und der Beschäftigung in Österreich bis 2035, VID Working Paper 03/2007.

Feichtinger, Gustav, Maria Winkler-Dworak, Inga Freund, and Alexia Prskawetz, On the Age Dynamics of Learned Societies: Taking the Example of the Austrian Academy of Sciences, VID Working Paper 02/2007.

Winkler-Dworak, Maria and Laurent Toulemon, Gender Differences in the Transition to Adulthood in France: Is There Convergence Over the Recent Period? VID Working Paper $01 / 2007$.

Prskawetz, Alexia, Marija Mamolo, and Henriette Engelhardt, Reconsidering the Relation between Fertility and Key Fertility-Related Demographic Behaviour across Space and Time, VID Working Paper 09/2006.

Mamolo, Marija, Union Formation, Marriage and First Birth: Convergence Across Cohorts in Austria, Hungary, Northern Italy and Slovenia? VID Working Paper 08/2006.

Goujon, Anne and Samir K.C., Past and Future of Human Capital in Southeast Asia: From 1970 to 2030, VID Working Paper 07/2006.

Lyngstad, Torkild H., Does Community Context have Important Bearings on the Divorce Rate? VID Working Paper 06/2006.

Winkler-Dworak, Maria, The Low Mortality of a Learned Society, VID Working Paper 05/2006.

Kim, Jungho and Alexia Prskawetz, External Shocks, Household Consumption and Fertility in Indonesia, VID Working Paper 04/2006.

Schwarz, Franz, Behavioral Explanation for Educational Health and Mortality Differentials in Austria, VID Working Paper 03/2006.

Schwarz, Franz, The Contributions of Diseases to Increasing Educational Mortality Differential in Austria, VID Working Paper 02/2006.

The Vienna Institute of Demography Working Paper Series receives only limited review. Views or opinions expressed herein are entirely those of the authors. 